\title{
Epidemiology of Respiratory Syncytial Virus Infection in Preterm Infants
}

\author{
Bernhard Resch $^{1, *}$, Stefan Kurath ${ }^{1}$ and Paolo Manzoni ${ }^{2}$ \\ ${ }^{I}$ Research Unit for Neonatal Infectious Diseases and Epidemiology, Division of Neonatology, Pediatric Department, \\ Medical University Graz, Austria \\ ${ }^{2}$ Division of Neonatology and NICU, S. Anna Hospital. AO O.I.R.M-S. Anna, Torino, Italy
}

\begin{abstract}
This review focuses on the burden of respiratory syncytial virus (RSV) infection in preterm infants with and without chronic lung disease (bronchopulmonary dysplasia, BPD). The year-to-year and seasonal variations in RSV activity are key aspects of RSV epidemiology, and knowledge/monitoring of local RSV activity is mandatory for guidance of prophylaxis with the monoclonal antibodies palivizumab and in the near future motavizumab. Morbidity expressed in rates of hospitalizations attributable to RSV illness revealed a mean of 10 percent in preterm infants without and 19 percent $(\mathrm{p}=0.016)$ with BPD. Mortality rates diverged widely, and case fatality rates have been reported to range from 0 to 12 percent. The typical clinical picture of lower respiratory tract infection is not different in term and preterm infants, but rates of apnoeas are significantly increased in preterms, ranging from 4.9 to 37.5 percent with decreasing rates observed in more recent studies. Until a RSV vaccine is developed and will be available, prophylaxis with palivizumab is the only preventative strategy other than hand hygiene and contact measures that significantly reduces RSV hospitalization rates in preterm infants both with and without BPD.
\end{abstract}

Keywords: Bronchopulmonary dysplasia, monoclonal antibodies, palivizumab, preterms, preventative strategy.

\section{INTRODUCTION}

Respiratory syncytial virus (RSV) is the most important cause of lower respiratory tract infection in infants and children. Fifty to 90 percent of hospitalizations for bronchiolitis, 5 to 40 percent of those for pneumonia, and 10 to 30 percent of those for tracheobronchitis are caused by RSV [1]. Substantial increases in the number of admissions for RSV bronchiolitis (up to 126.300 hospitalizations and 500 deaths annually) have been documented in North America [2]. In Canada, inpatient care of RSV illness costs \$ 18 million (US dollars) yearly, accounting for 62 percent of the total cost of this disease [1]. The magnitude of the costs is understandable, since virtually all children become infected with RSV within two years after birth, and one percent requires hospitalization [3].

In developed countries, there are well-defined high-risk groups, generally with chronic underlying disorders, in whom infection with RSV is more likely to progress into severe lower-respiratory-tract infections. Healthy infants younger than 3 months old are also susceptible to such infections. High risk groups for severe RSV disease include infants below six months of age, premature infants with or without chronic lung disease (bronchopulmonary dysplasia BPD), infants with hemodynamically significant congenital heart disease (CHD), immunosuppressed patients (including

*Address correspondence to this author at the Division of Neonatology, Pediatric Department, Medical University of Graz, Auenbruggerplatz 30, A-8036 Graz, Austria; Tel: 0043316385 81134; Fax: 0043316385 2678; E-mail: bernhard.resch@medunigraz.at those undergoing chemotherapy, bone-marrow and solidorgan transplantation, and those with underlying disorders of cellular immunity) or cystic fibrosis, and infants with neuromuscular diseases [4-6]. There is no particular age-group that is not at risk for RSV infection, but certain risk factors have been implicated in more severe disease:low socioeconomic status, crowded living conditions, exposure to indoor smoke pollution, a family history of asthma or atopy, and perhaps infection with the A subgroup of RSV [4]. Preterm infants with or without BPD and infants with CHD are also known to be at increased risk for hospitalization including admission to an intensive care unit (ICU), ventilatory support, or prolonged supplemental oxygen [7-9].

This review focuses on the burden of RSV disease in preterm infants with and without BPD.

\section{SEASONAL DISTRIBUTIONS OF RSV RELATED HOSPITALIZATIONS OF PRETERM INFANTS}

The year-to-year and seasonal variations in RSV activity are key aspects of RSV epidemiology. RSV is a seasonal virus, with peak rates of infection occurring annually in the cold season in temperate climates, and in the rainy season, as temperatures fall, in tropical climates [4]. Among Europe RSV related re-hospitalizations of preterm infants show a seasonal distribution mainly during the winter and spring months ranging from October to May, and peaking between December/January and March [9-14]. The distribution of hospitalizations and ICU admissions related to confirmed RSV infection throughout the study period (IRIS study) peaked in December and January [14] and the distribution of RSV related re-hospitalizations in the Munich RSV Study 
extended from October to May, with 29 cases $(75.7 \%)$ occurring between January and March [10]. The Austrian RSV 29-32 Study Group including 863 infants aged 29 to 32 weeks of gestational age revealed $18 \%$ of RSV related rehospitalizations occurring outside the typical RSV season [11]. An even higher rate has been reported by Duppenthaler et al., [15] during the 1999/2000 RSV season in Switzerland with $36 \%$ of hospitalisations occurring after April 1, 2000 that would not have been preventable by palivizumab prophylaxis initiated in November 1. Overall there are major differences between regions throughout the northern hemisphere [16-22]. In the southern hemisphere, for example in Gambia, RSV activity peaked during the summer months between August and September over a 4-year (1993 - 1996) period [23].

Thus, knowledge about local RSV epidemics is mandatory for targeted prophylaxis with palivizumab in high-risk infants. In Austria an epidemiological monitoring system has been established in 2002 called RSV-hotline incorporating data of infants hospitalized due to RSV disease that are entered into the system voluntarily by Austrian pediatricians (https://hc4you.hcsolutions.at/rsv). The seasonal distributions of RSV attributed hospitalizations of preterm infants in Austria over the seasons 1998 to 2001 and 2001 to 2003 are shown in Fig. (1a, b), respectively $[11,24]$.

\section{CLINICAL FEATURES OF RSV INFECTION IN PRETERM INFANTS}

The most common infection caused by RSV is of the upper respiratory tract; such infections are characterised by rhinitis, cough, and sometimes fever. Acute otitis media occurs in up to a third of children with RSV illness; both RSV and bacterial pathogens have been isolated from the middle ears of children with RSV. Croup also occurs with RSV in-

a

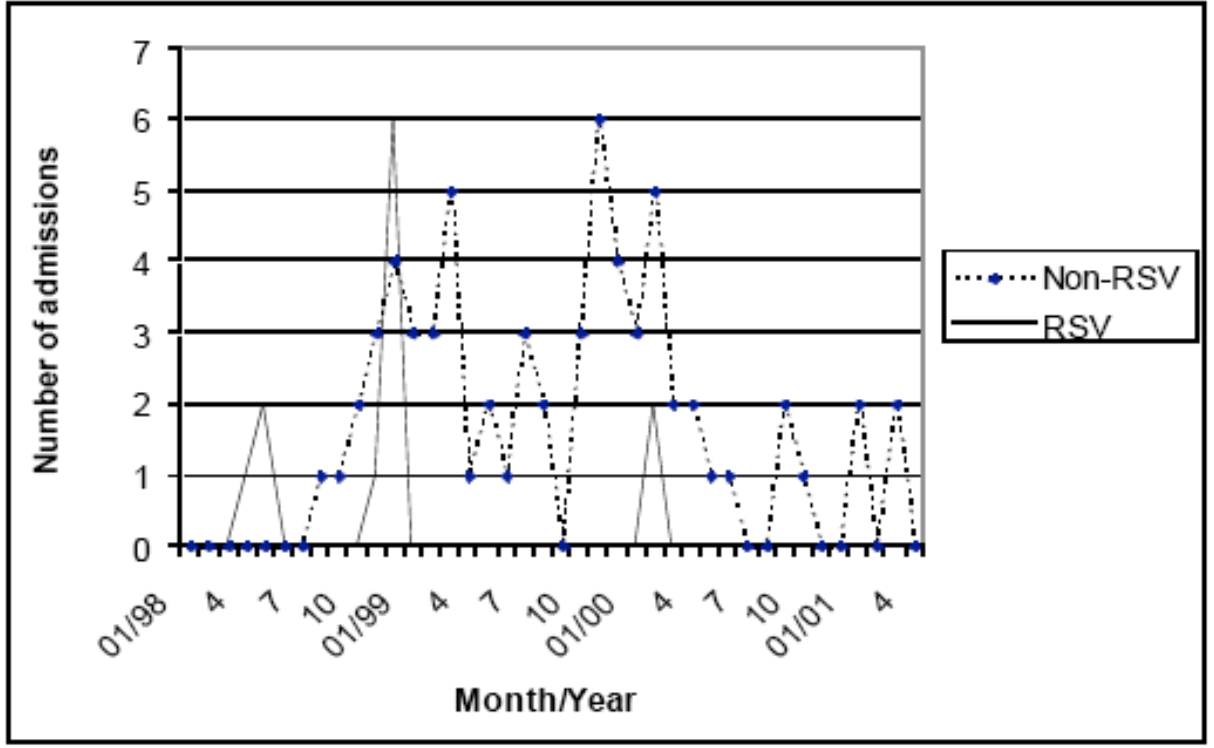

b

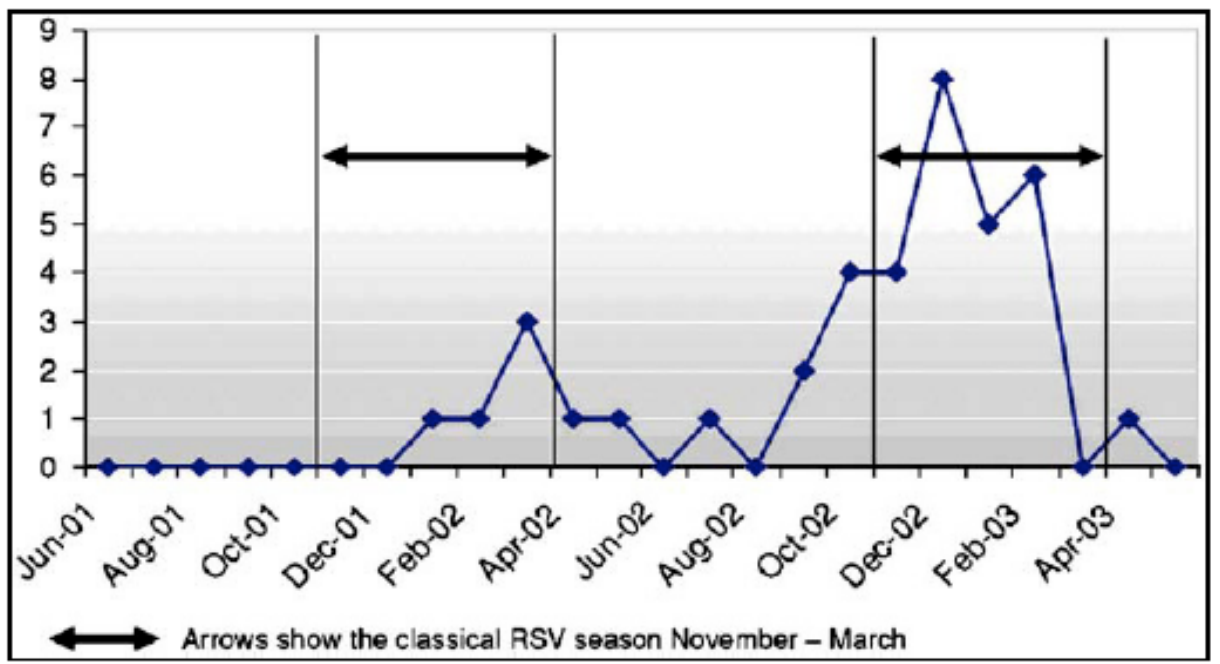

Fig. (1) (a). Seasonal distribution of rehospitalisations due to respiratory illness (proven RSV and non-RSV infections) in premature infants of 29-36 weeks gestational age [24]. (b). Seasonal distribution of RSV hospitalizations $(n=38)$ in premature infants of 29-32 weeks' gestational age between 1 June 2001 and 1 June 2003 [11]. 
fection, but bronchiolitis and pneumonia are the most common manifestations in children. Signs of upper-respiratorytract involvement commonly precede those of the lower respiratory tract by a few days, and fever, when present, is usually low grade. Dyspnoea, lower chest-wall indrawing, and difficulty in feeding characterise lower-respiratory-tract infection. In bronchiolitis, wheeze may be audible with or without a stethoscope, and a prolonged expiratory phase and crackles are characteristic. Air trapping results in very fast breathing and a palpable liver and spleen. The typical radiographic pattern includes hyperinflation with diffuse interstitial markings and peribronchial thickening. Segmental atelectasis, which usually clears spontaneously, is often seen. Children with pneumonia, on the other hand, have fine crackles and a radiographic pattern of alveolar, segmental, or lobar consolidation.

Severe bronchiolitis may lead to acute respiratory failure associated with severe bronchospasm, moderate to severe hypoxia, and carbon dioxide retention. With lung function tests [25] two patterns of severe disease are seen: in about two-thirds of cases there is obstructive small airways disease (bronchiolitis), and in the remainder there is a restrictive pattern (pneumonia). Most of the latter cases meet the criteria for acute respiratory distress syndrome. They tend to be younger, have more predisposing underlying disease, and are ventilated for longer. In severely ill children, complications include pulmonary hypertension and cardiovascular compromise requiring inotropic support [26].

Although bacterial superinfection is rare in developed countries, it is more common in developing countries. This may partly explain the higher fatality rates seen in developing nations [4]. Over a five years period we observed a general low total rate of bacterial co-infection of $1.9 \%$ excluding ICU patients [27]. The risk of concurrent bacterial infection in preterm infants hospitalized due to respiratory syncytial virus infection was three times higher compared to term infants $(9.5$ vs. $3.1 \%, \mathrm{p}=0.017)$ and associated with prolonged hospitalisation and ICU admission). The predominant pathogens were Streptococcus pneumoniae and Haemophilus influenzae. Mean length of stay in preterm infants with bacterial co-infection was 22.3 days compared to 10.3 days without bacterial co-infection ( $\mathrm{p}<0.006)$.

Apnoea tends to occur in infants under 2 months of age with atelectasia on chest radiography [28] and is common in those born prematurely. In cases of severe apnoea, mechanical ventilation may be necessary, despite the absence of respiratory failure. The pathophysiology of this manifestation is unknown, but postulated mechanisms include the immaturity of the respiratory centre in the brain-stems of premature infants, and RSV associated hypersensitivity of the laryngeal chemoreceptors [4]. In a recent systematic review the incidence of apnoea including a study population of 5575 hospitalized patients with RSV ranged from a high of $23.8 \%$ to a low of $1.2 \%$ [29]. Comparison of the cohort by term and preterm birth revealed an expected excess in apnoea incidence in preterms, even in the absence of information about chronologic age In detail, the authors cite five of seven studies reporting on the incidence of apnoea with significant rates comparing term to preterm infants (range $0.5-12.4 \%$ compared to $4.9-37.5 \%$, respectively, overall $\mathrm{p}<0.001$ ), see Table 1 [29]. A study by Gleeson et al., [30] examined the hypothesis that dysregulation of mucosal immune responses to respiratory infections is a critical event, which could be causal in respiratory arrest of some previously healthy infants. The salivary IgA and IgM concentrations in the apparent life threatening event (ALTE) infants at presentation to hospital indicated that a significant mucosal immune response had already occurred with nearly $60 \%$ of the $\operatorname{IgA}$ concentrations significantly above the population-based reference ranges. This hyper-immune response was most evident in the ALTE infants with pathology evidence of an infection; and the most prevalent pathogen identified was RSV $(64 \%)$. The group compromised 26 infants with a gestational age ranging from 26 to 41 weeks at a median age of 60 days.

Table 1. Incidence of RSV Associated Apnea by Term $(\geq 37$ Weeks' Gestation) Versus Preterm Birth [29]

\begin{tabular}{|l|l|l|l|}
\hline Study & Term & Preterm & p-value \\
\hline \hline Simon et al., 2007 & $0.6 \%$ & $4.9 \%$ & $<.001$ \\
\hline Willwerth et al., 2006 & $0.5 \%$ & $9.9 \%$ & $<.001$ \\
\hline Bergstrasser et al., 1998 & $6.7 \%$ & $17.6 \%$ & $\mathrm{NS}$ \\
\hline Meert et al., 1990 & $4.0 \%$ & $5.3 \%$ & $\mathrm{NS}$ \\
\hline Church et al., 1984 & $11.2 \%$ & $33.7 \%$ & $<.001$ \\
\hline Colditz et al., 1982 & $5.1 \%$ & $32.1 \%$ & $<.001$ \\
\hline Bruhn et al., 1977 & $12.4 \%$ & $37.5 \%$ & $<.001$ \\
\hline
\end{tabular}

From: Ralston S, Hill V Incidence of apnea in infants hospitalized with respiratory syncytial virus bronchiolitis: a systematic review. J Pediatr 2009; 155:728-33 [29].

Encephalopathy associated with respiratory syncytial virus infection is not well recognized. $\mathrm{Ng}$ et al., [31] reported on an incidence of $1.8 \%$ in a total of 487 patients with respiratory syncytial virus bronchiolitis studied over a period of four years with seizures being the presenting complication. Interestingly, three of the nine infants showing neurologic complications had a history of prematurity $(27,28$, and 31 weeks of gestational age, respectively).

During a five-year period (1984 to 1989) Meert et al., [7] reported on 484 previously healthy infants (including $27 \%$ preterm born) admitted to the hospital with RSV infection. No differences were found in the presenting symptoms of respiratory distress, cough, fever or shock, although the preterm group was more likely to present with apnea (13 vs. $4 \%, \mathrm{p}<0.001)$. Chest roentgenograms revealed that preterm infants had a higher incidence of atelectasis/infiltrate and hyperinflation (47vs. 36\%, p<0.05, and $28 v s .19 \%, \mathrm{p}<0.05$, respectively). Preterm infants had longer hospital stays (mean 5.4 vs. 3.6 days, $\mathrm{p}<0.001$ ) as well as a higher Physiologic Stability Index and Therapeutic Intervention Score (6.4 vs. 4.3, $\mathrm{p}<0.001$, and 7.4 vs. 5.4, $\mathrm{p}<0.001$, respectively). They were also more likely to receive supplemental oxygen (39 vs. 19\%), ICU admission (13 vs. 4\%), mechanical ventilation (12 vs. $2 \%$ ), and nothing by mouth status (17 vs. $7 \%$, for all $\mathrm{p}<0.001$, respectively). There was no difference in postnatal age (mean $5.5 \mathrm{vs}$. 5.1 months), but preterm infants had a younger postconceptual age (mean 3.9 vs. 5.0 months, $\mathrm{p}<0.05)$. 
The 37 preterm infants with RSV related rehospitalisation of the Munich RSV study [10] presented with pneumonia with and without clinical signs of obstructive bronchitis (27\%); obstructive bronchitis, bronchiolitis, or acute bronchitis $(67.6 \%)$ or acute upper airway infection $(5.4 \%)$.

\section{MORBIDITY AND MORTALITY DUE TO RSV IN- FECTION IN PRETERM INFANTS WITH AND WITHOUT BRONCHOPULMONARY DYSPLASIA}

\section{Morbidity}

The risk for RSV related hospitalization is significantly increased in preterm infants. In East Denmark the incidence of RSV infection requiring hospitalization among infants $<6$ months was estimated to be $34 / 1000 /$ season, and was $32 / 1000 /$ season among term infants and 66/1000/season among preterm infants $(\mathrm{p}<0.001)$ [8]. In Southern Austria we observed an incidence of RSV infection requiring hospitalization of 6/1000/season among term and 12/1000/season $(\mathrm{p}<0.05)$ among preterm infants [32].

Why are preterm infants at increased risk for severe RSV lower respiratory tract infection? The main factors include small lung volumes, a reduced lung surface area, small airways and an increased air space wall thickness [33]. This is reflected by the developmental stage of the fetal lungs showing the canalicular period between 16 and 26 weeks followed by the saccular period from 26 to 36 weeks and at least the alveolar period from 36 to 41 weeks of gestational age. For example, the lung volume and surface area of a term are three times larger compared to a 30 week preterm infant. Additionally, the airways of preterm infants have been ventilated mechanically and been suctioned and thus been damaged by many microtraumas with disruption of endothelial surfaces enabling pathogens easier to invade. At least the immune system of preterm infants is immature resulting in low antibody titers (incomplete diaplacentar transfer of maternal antibodies) and a reduced cellular immunity with reduced virus clearance [34].

Groothuis [35] first reported on the increased risk of preterm infants with bronchopulmonary dysplasia (BPD) for RSV related prolonged hospitalizations, high rates of admission to the ICU and the need for mechanical ventilation. Early data from the PICNIC study group including twelve paediatric tertiary care centers during the 1989 to 1990 season observed $12.6 \%$ of hospitalized infants with RSV infection having chronic lung disease and $23.9 \%$ being born prematurely [36]. Another data from the PICNIC study group found underlying illnesses including chronic lung disease like bronchopulmonary dysplasia significantly associated with prolonged hospital stay attributable to RSV compared with those who were premature or younger than 6 weeks of age on admission [37]. The proportion of infants with underlying illness was $22.6 \%$ in a study population of 689 patients, $16 \%$ were admitted to ICU and $9.1 \%$ needed mechanical ventilation. The mortality rates varied across all groups, and the rate was $0.9 \%$ in the total study population

Joffe et al., [38] reported on a median length of stay for RSV disease in preterm infants $<37$ weeks gestational age of 4 days. Infants who were discharged from the NICU and rehospitalized during the same RSV season tended to have longer admissions than those discharged before the begin- ning of the season, and they also required more days of oxygen therapy, had a higher risk for ICU admission, and were more likely to require mechanical ventilation. No deaths were reported attributable to RSV.

The Spain case control study (IRIS study group) in infants of 33 to 35 weeks gestational age linked to RSV related hospitalization (including 186 cases and 371 controls) reported on a rate of $20.5 \%$ requiring ICU admission and $7.6 \%$ with need for mechanical ventilation [39]. During the study period no deaths were observed. Median length of stay in hospital was 8 days and in ICU 6 days. The IRIS study reported on fifty-nine preterm infants below 33 weeks of gestational age being rehospitalized for RSV infection of whom $15(25.4 \%)$ required ICU admission for a median of 6 (range 3 to 11 ) days and three $(5.1 \%)$ mechanical ventilation for a median of 5 (range 7 to 43) days [14].

During a prospective study on infants younger than 24 months hospitalized for viral upper and lower respiratory tract infection between November 1999 and October 2000 we found 58 of 281 (21\%) infants included being RSV positive by antigen detection in nasopharyngeal aspirates [9]. RSV positive infants were of younger age (mean $3.5 \mathrm{vs} .5 .5$ months, $\mathrm{p}=0.003$ ), had a higher lower respiratory illness score (ranging from 0 to 5; mean 2.9 vs. 1.8, p<0.001), and had more days of hospitalization, more days of oxygen requirement, and more days of respiratory support (all $\mathrm{p}<0.001$, respectively). Comparison of RSV-positive U/LRTI of preterm with term infants showed differences only regarding days of hospitalization (mean 14 vs 8.9; $\mathrm{p}=0.007$ ). Thus, RSV contributed to prolonged hospitalizations and more severe clinical courses of disease both in very young term and preterm infants.

Of 151 children under 1 year of age admitted to the paediatric intensive care unit (PICU) of the Trousseau Hospital in Paris from 1 January 1996 to 31 December 2003 for management of bronchiolitis caused by proven RSV infection and requiring mechanical ventilation 14 infants $(9.1 \%)$ needed extracorporeal membrane oxygenation (ECMO) support [40]. The frequency of BPD was significantly higher amongst children who required ECMO support as compared with those from the group without ECMO support $(\mathrm{p}=0.001$, $\mathrm{OR}=8.9 ; 95 \% \mathrm{CI}=2.4-33.1$ ).

The rate for re-hospitalisation due to acute respiratory infection was $10.6 \%$ of 717 preterm infants ( $<35$ weeks gestational age) included in the Munich RSV study, and the risk for RSV related hospitalization was 5.2\% during a one year observation period [10]. Preterm infants with BPD had a probability of $24.5 \%$ for rehospitalisation due to acute respiratory infection and of $15 \%$ for RSV related hospitalization. The following factors were independently associated with an increased risk of RSV related hospitalization: male gender (adjusted OR: 8.7; 95\% CI 2.6-29.1), chronic lung disease (OR: 3.99; 95\%CI: 1.4-11.2), discharge between October and December (OR: 2.1; 95\%CI: 0.99-4.4), and day-care attendance of siblings (OR: 3.9; 95\%CI: 1.9-8.3). The median length of hospital stay was 8 days (range 2-48 days). Thirty-one infants $(83.7 \%)$ were treated in regular pediatric wards, whereas six infants $(16.2 \%)$ required intensive-careunit admission for a median duration of 6.5 days (range 4-8 days). 
Assessing the effect of prematurity on RSV hospital resource use and outcomes by comparison of different gestational age-groups ( $<33,33$ to 35 , and 36 weeks, respectively) resulted in higher intubation rates and longer stays at the hospital and the ICU in infants aged 33 to 35 weeks [41]. Infants 36 weeks gestational age had outcomes similar to term infants. Another study focusing on complications in infants hospitalized for RSV disease interestingly showed former preterm infants of 33 to 35 weeks gestational age having the highest rates of complications (93\%), the longest mean hospital stay of 7.4 days and the highest costs out of the group with a history of prematurity [42].

Table 2 summarizes the published data on rehospitalization rates as a marker of severe RSV infection in preterm infants without BPD [10-14,24,38,39,43-52], and Table 3 those with BPD [10,12,14,35,44-46,53]. The mean RSV hospitalization rate of preterm infants was shown to be about $10 \%$ with a wide range from 0 to $44 \%$ (Alaska native children). This mean rate was significantly increased to $19 \%$ $(\mathrm{p}=0.016)$ in preterm infants with BPD (range 8.8 to $36.7 \%$ ).

\section{Mortality}

In children younger than 5 years and particularly in those aged under 1 year RSV is the most common viral cause of death, resulting in an estimated RSV-associated mortality rate of 3.2 per 100.000 person-years for the 1990/91 through 1998/99 seasons in the United States [54]. A review of the literature revealed a RSV case fatality rate ranging from 0 to
$12 \%$ including 15 studies of developed countries and a rate ranging from 0 to $9.1 \%$ including 21 developing countries [55].

Table 3. Rates of RSV Related Hospitalization (\%) in Preterm Infants with Bronchopulmonary Dysplasia [10,12,14, $35,44-46,53]$

\begin{tabular}{|l|c|c|}
\hline Author, Year, Reference & $\begin{array}{c}\text { Number of } \\
\text { Patients (n) }\end{array}$ & $\begin{array}{c}\text { Hospitalization } \\
\text { Rate (\%) }\end{array}$ \\
\hline \hline Groothuis, 1988 [35] & 30 & $36.7 \%$ \\
\hline Prevent Study, 1997 [44] & 149 & $17.4 \%$ \\
\hline IMpact Study 1998 [45] & 266 & $12.8 \%$ \\
\hline Stevens, 2000 [12] & 131 & $25.2 \%$ \\
\hline Thomas, 2000 [46] & 34 & $8.8 \%$ \\
\hline IRIS Study, 2000 [14] & 53 & $15 \%$ \\
\hline Greenough, 2001 [53] & 235 & $19.1 \%$ \\
\hline Liese, 2003 [10] & 53 & $15 \%$ \\
\hline
\end{tabular}

Over a study period covering eight consecutive RSV seasons Thorburn [56] reported on 406 RSV-positive patients admitted to PICU. Eighteen patients died due to RSV bronchiolitis resulting in an ICU mortality rate of $4.4 \%$ and a

Table 2. RSV Related Hospitalization Rates for Preterm Infants Without Chronic Lung Disease/ Bronchopulmonary Dysplasia [10-14,24,38,39,43-52]

\begin{tabular}{|c|c|c|c|c|}
\hline Author, Year, Reference & Infants (n) & GA (weeks) & Chronologic Age (Months) & Hospitalization Rate (\%) \\
\hline Nachmann 1997 [43] & 1034 & $<2500$ grams & $<12$ & 4.0 \\
\hline IMpact study 1998 [45] & 740 & $\leq 35$ & $\leq 6$ & 8.1 \\
\hline Joffe 1999 [38] & 1721 & $23-36$ & 1st RSV season & 3.2 \\
\hline Thomas 2000 [46] & 48 & $<32$ & 1st RSV season & $0-2.0$ \\
\hline Stevens 2000 [12] & 1029 & $\leq 32$ & $\leq 12$ & 7.6 \\
\hline Carbonell-Estrany 2001 [47] & 999 & $\leq 32$ & 1st RSV season & 13.1 and 13.4 \\
\hline Pedersen 2003 [49] & 240 & $<28$ and/ or $<1000$ grams & $\leq 24$ & 18.0 \\
\hline Singleton 2003 [50] & N/A & $<36$ & $<12$ & 43.9 \\
\hline Law 2004 [51] & 1832 & $33-35$ & 1st RSV season & 3.6 \\
\hline Resch 2005 [24] & 435 & $29-36$ & $\leq 6$ & 4.4 \\
\hline Resch 2006 [11] & 801 & $29-32$ & $<24$ & 4.5 \\
\hline Doering 2006 [52] & 1158 & $29-35$ & $<12$ & 4.2 \\
\hline Figueras 2008 [39] & 5441 & $32-35$ & $\leq 6$ & 3.7 \\
\hline
\end{tabular}


total hospital RSV mortality rate of $1.7 \%$. All of the RSV deaths were reported to have pre-existing medical conditions including chronic lung disease in $12 \%$, but a history of prematurity was not predictive of death.

Sampalis [57] evaluated the impact of RSV infections on subsequent health care resource utilization in preterm infants. Of data from 2415 preterm infants (32 to 35 weeks gestational age) hospitalized for proven or probable RSV and matched to 20,254 control infants the overall mortality rate was $8.1 \%$ for the RSV cohort and $1,6 \%$ for the controls $(\mathrm{p}<0.001)$. The author concluded that RSV hospitalization in healthy premature infants was associated with a significant increase in subsequent health care resource utilization and mortality.

\section{PREVENTION OF RSV INFECTION WITH PALIVI- ZUMAB}

In the early 1960s, vaccination of infants with a formalininactivated RSV vaccine failed to be successful despite significant increases of compliment fixatory antibodies in the vaccinated infants $[58,59]$. The vaccine augmented the severity of wild virus infection and led to the death of two infants in the following season. Standard polyclonal immunoglobulin preparations containing substantial levels of neutralizing antibodies to RSV were not successful in the prevention of RSV hospitalisation. In contrast, the hyperimmmune RSV globulin $\left(\right.$ RespiGam ${ }^{\circledR}$ ) given intravenously at dosages of 750 $\mathrm{mg} / \mathrm{kg}$ monthly over the RSV season proved to be save and effective in prevention of lower respiratory tract infections in high-risk preterm infants and young children [60]. Children with cyanotic congenital heart disease however were more likely to experience adverse events, such as sudden unexplained death associated with cardiac surgery, if they received RSV-IGIV. Thus, recommendations for the use of RSV-IGIV published by the American Academy of Pediat- rics excluded those infants with CHD [61]. Despite its efficacy, RSV-IGIV had the disadvantage of monthly infusions that were cumbersome, expensive, time-consuming, and stressful for both the patient and the parents, and there was always the remote possibility of blood-borne pathogen transmission. The development of a highly potent RSVneutralizing monoclonal antibody (Mab) was the next approach to improve the specific activity of anti-RSV immunoglobulin. In 1997, researchers at MedImmune, Inc. developed a humanized murine monoclonal antibody called palivizumab $\left(\right.$ Synagis ${ }^{\circledR}$ ) that recognizes a conserved neutralizing epitope at the "A" region on the F glycoprotein of RSV [62].

In a randomized, placebo controlled (palivizumab:placebo 2:1), double-blind, multicenter phase III trial including 139 centers in the United States, Canada, and the United Kingdom 1502 young children with prematurity $(\leq 35$ weeks of gestation, $\leq 6$ months of age) or bronchopulmonary dysplasia $(\leq 24$ months of age, requiring medical treatment within the past 6 months for their chronic lung disease) were included during the 1996 to $1997 \mathrm{RSV}$ season to receive 5 monthly (every 30 days) injections of either $15 \mathrm{mg} / \mathrm{kg}$ palivizumab or an equivalent volume of placebo intramuscularly [45]. Children were followed 150 days for the primary endpoint hospitalization due to RSV infection. Ninety-nine percent of the children in both groups completed the study protocol and 93\% received all five scheduled injections. Palivizumab prophylaxis resulted in a 55\% reduction in hospitalization as a result of RSV infection. Details of study results including secondary outcome measures are presented in Table 4 [45].

The incidence of RSV related hospitalization following palivizumab prophylaxis was assessed in several retrospective and prospective studies conducted in Europe and North America [63]. In general, the incidence of RSV related hospital admissions after palivizumab prophylaxis in postmarketing surveillance studies was lower than the reported

Table 4. Results from the IMpact Study, a Randomized Placebo Controlled Trial on Palivizumab in Preterm Children with and Without Bronchopulmonary Dysplasia [45]

\begin{tabular}{|c|c|c|c|c|}
\hline RSV Hospitalization & $\begin{array}{c}\text { Palivizumab } \\
\mathrm{n}=\mathbf{1 0 0 2}\end{array}$ & $\begin{array}{l}\text { Placebo } \\
\mathbf{n}=\mathbf{5 0 0}\end{array}$ & Relative Reduction (\%) & p-Value* \\
\hline Preterm infants $\leq 35$ weeks (including BPD) & $4.8 \%$ & $10.6 \%$ & $55 \%$ & $<0.001$ \\
\hline Preterm infants $\leq 35$ weeks (no BPD) & $1.8 \%$ & $8.1 \%$ & $78 \%$ & $<0.001$ \\
\hline all BPD & $7.9 \%$ & $12.8 \%$ & $39 \%$ & 0.038 \\
\hline Preterm infants $32-35$ weeks (no BPD) & $1.8 \%$ & $10.0 \%$ & $82 \%$ & $<0.001$ \\
\hline Total days hospitalization/ 100 children & 36.4 & 62.6 & - & $<0.001$ \\
\hline Total days with supplemental oxygen & 30.3 & 50.6 & - & $<0.001$ \\
\hline Total days with LRI-score $\geq 3$ & 29.6 & 47.4 & - & $<0.001$ \\
\hline ICU admission & $1.3 \%$ & $3 \%$ & - & 0.026 \\
\hline Total ICU days & 12.7 & 13.3 & - & 0.023 \\
\hline Mechanical ventilation & $0.2 \%$ & $0.7 \%$ & - & 0.280 \\
\hline Total days of mechanical ventilation & 1.7 & 8.4 & - & 0.210 \\
\hline
\end{tabular}

$\mathrm{BPD}=$ bronchopulmonary dysplasia, LRI-score $=$ lower respiratory tract infection score $(0=$ no illness, $5=$ mechanical ventilation $)$, ICU $=$ intensive care unit * Fisher's exact test 
Table 5. RSV Rehospitalization Rates in Preterm Infants with and Without Bronchopulmonary Dysplasia Having Received Palivizumab from the Palivizumab Outcomes Registry [64]

\begin{tabular}{|c|c|c|c|c|}
\hline & $\begin{array}{c}2000-2001 \\
(\mathbf{n = 2 0 4 9})\end{array}$ & $\begin{array}{c}\mathbf{2 0 0 1 - 2 0 0 2} \\
(\mathbf{n = 5 0 8 4})\end{array}$ & $\begin{array}{c}\mathbf{2 0 0 2 - 2 0 0 3} \\
(\mathbf{n = 6 2 9 1})\end{array}$ & $\mathbf{1 , 1}$ \\
\hline \hline All preterm infants & $\mathbf{2 , 9}$ & $\mathbf{1 , 5}$ & $\mathbf{1 , 2}$ & $\mathbf{0 , 7}$ \\
\hline without BPD/ CLD & $\mathbf{2 , 1}$ & $\mathbf{1 , 2}$ & $\mathbf{1 , 6}$ & $\mathbf{0 , 7}$ \\
\hline$<32$ weeks & $\mathbf{4 , 5}$ & $\mathbf{1 , 7}$ & $\mathbf{0 , 7}$ & $\mathbf{1 , 1}$ \\
\hline $32-35$ weeks & $\mathbf{1 , 6}$ & $\mathbf{1 , 3}$ & $\mathbf{1 , 9}$ & $\mathbf{1 , 8}$ \\
\hline BPD/ CLD & $\mathbf{5 , 8}$ & $\mathbf{2 , 2}$ & \\
\hline
\end{tabular}

rates of the IMpact study [46]. Data from the American Palivizumab Outcomes Registry provide the largest data set available on infants born prematurely with or without BPD and children with CHD (55-58) and are summarized in Table 5 [64].

Data from the French Pediatricians' Group of Synagis Patients' Name-Based Programs reported on $7.6 \%$ rehospitalisation rate in a population of 515 infants with a high rate of $81 \%$ of the infants included having BPD [65]. In the large Spanish trial of the IRIS Study Group [48] including two study cohorts of a total of 3502 infants over four RSV seasons (1998 to 2002) an overall reduction of $70 \%$ of RSV related hospital admissions in premature infants with and without BPD was demonstrated. Infants without prophylaxis had a 4-fold increased risk of RSV hospitalization. No deaths were reported in palivizumab recipients.

Adherence to the monthly injections scheme of palivizumab prophylaxis remains a major problem. Parnes et al., [66] noted lower re-hospitalisation rates in infants with higher adherence to this scheme, and they observed that approximately half of RSV related hospitalizations occurred between the first and second injection. Similar findings were also reported by Manzoni et al., [67], consistent with the trends of serum palivizumab levels that may still be inadequate and not fully prototective after the first monthly dose [68]. Missed or delayed palivizumab injections resulted in an increase of RSV related hospitalizations from $2.4 \%$ to $4.4 \%$ $(\mathrm{p}=0.02)$. In comparison of a home versus office setting during the 2000/2001 season 969 infants received palivizumab injections at home by a nurse and 477 in the office of a pediatrician [69]. Comparing home versus office, compliance was $98 \%$ compared with $89 \% \quad(\mathrm{p}<0.001)$, and RSV related hospitalization rate was $0.93 \%$ compared with $3.57 \%$ ( $\mathrm{p}<0.001)$. During a multicenter observational study of respiratory syncytial virus-associated hospitalizations and use of palivizumab in premature infants aged 29-32 weeks over two RSV seasons (2001 to 2003) in Austria 238 infants received palivizumab prophylaxis [11]. The rate of inadequate or incomplete injections was very high $(62 \%)$ resulting in an increased rehospitalisation rate of $8.1 \%$ compared with $3.3 \%$ of adequate prophylaxis $(12 / 148$ vs. $3 / 90, \mathrm{p}=0.07)$.

\section{CONCLUSION}

A vaccine for RSV is needed, and a protective live attenuated vaccine administered at or around birth would be ideal. However, problems like insufficient attenuation of the vaccine strain of RSV, its thermolability, and the need to include $\mathrm{A}$ and $\mathrm{B}$ strains in each vaccine have hindered trials in infants under 3 months of age [4]. Prevention of RSV related hospitalizations in preterm infants by monthly injections of monoclonal antibodies like palivizumab or in the near future motavizumab is recommended in selected highrisk groups [70] but still discussed due to the high costs of the product. Recent studies focused on RSV risk factor models aiming to tailor prophylactic treatment with monoclonal antibodies to those preterm infants with the highest risk for severe RSV related disease [71-74]. Until a vaccine is developed efforts to offer prophylaxis to high-risk infants is mandatory.

\section{CONFLICT OF INTEREST}

None declared.

\section{ACKNOWLEDGEMENTS}

None declared.

\section{REFERENCES}

[1] Hall CB. Respiratory syncytial virus and parainfluenza virus. N Engl J Med 2001; 344: 1917-28.

[2] Shay DK, Holman RC, Newman RD, Liu LL, Stout JW, Anderson LJ. Bronchiolitis-associated hospitalizations among US children, 1980-1996. JAMA 1999; 282: 1440-6.

[3] Glezen WP, Taber LH, Frank AL, Kasel JH. Risk of primary infection and reinfection with respiratory-syncytial virus. Am J Dis Child 1986; 140: 543-6.

[4] Simoes EAF. Respiratory syncytial virus infection. Lancet 1999 ; 354: 847-52.

[5] Arnold SR, Wang EE, Law BJ, et al. Variable morbidity of respiratory syncytial virus infection in patients with underlying lung disease: a review of the PICNIC RSV database. Pediatric Investigators Collaborative Network on Infections in Canada. Pediatr Infect Dis J 1999; 18: 866-9.

[6] Wilkesmann A, Ammann RA, Schildgen O, et al. Hospitalized children with respiratory syncytial virus infection and neuromuscular impairment face an increased risk of a complicated course, Pediatr Infect Dis J 2007; 26: 485-91.

[7] Meert K, Heidemann S, Abella B, Saeniak A. Does prematurity alter the course of respiratory syncytial virus infection? Crit Care Med 1990; 18: 1357-9.

[8] Kristensen K, Dahm T, Frederiksen PS, Ibsen J, Iyore E, Jensen AM, Kjaer BB, Olofsson K, Pedersen P, Poulsen S. Epidemiology of respiratory syncytial virus infection requiring hospitalisation in East Denmark. Pediatr Infect Dis J 1998; 17: 996-1000.

[9] Resch B, Gusenleitner W, Müller W. The impact of respiratory syncytial virus infection: a prospective study in hospitalized infants younger than 2 years. Infection 2002; 30: 193-7.

[10] Liese JG, Grill E, Fischer B, et al. Incidence and risk factors of respiratory syncytial virus-related hospitalizations in premature infants in Germany. Eur J Pediatr 2003; 162: 230-6. 
[11] Resch B, Gusenleitner W, Müller WD, Haas J. Observational study of respiratory syncytial virus-associated hospitalizations and use of palivizumab in premature infants aged 29-32 weeks. Eur J Clin Microbiol Infect Dis 2006; 25: 120-2.

[12] Stevens TP, Sinkin RA, Hall CB, Maniscalco WM, McConnochie KM. Respiratory syncytial virus and premature infants born at 32 weeks' gestation or earlier: hospitalization and economic implications of prophylaxis. Arch Pediatr Adolesc Med 2000; 154: 55-61.

[13] McCormick J, Tubman R. Readmission with respiratory syncytial virus RSV) infection among graduates from a neonatal intensive care unit. Pediatr Pulmonol 2002; 34: 262-6.

[14] Carbonell-Estrany X, Quero J, Bustos G, et al. Rehospitalization because of respiratory syncytial virus infection in premature infants younger than 33 weeks of gestation: a prospective study. IRIS Study Group. Pediatr Infect Dis J 2000; 19: 592-7.

[15] Duppenthaler A, Gorgievski-Hrisoho M, Aebi C. Regional impact of prophylaxis with the monoclonal antibody palivizumab on hospitalizations for respiratory syncytial virus in infants. Swiss Med Wkly 2001; 131: 146-51.

[16] Singleton RJ, Petersen KM, Berner JE, et al. Hospitalizations for respiratory syncytial virus infection in Alaska Native children. Pediatr Infect Dis J 1995; 14: 26-30.

[17] Banerji A, Lanctôt KL, Paes BA, et al. Comparison of the cost of hospitalization for respiratory syncytial virus disease versus palivizumab prophylaxis in Canadian Inuit infants. Pediatr Infect Dis J 2009; 28: 702-6.

[18] Howard TS, Hoffman LH, Stang PE, Simoes EA. Respiratory syncytial virus pneumonia in the hospital setting: length of stay, charges, and mortality. J Pediatr 2000; 137: 227-32.

[19] Purcell K, Fergie J. Driscoll Children's Hospital respiratory syncytial virus database: risk factors, treatment and hospital course in 3308 infants and young children, 1991 to 2002. Pediatr Infect Dis J 2004; 23: 418-23.

[20] Singleton RJ, Bruden D, Bulkow LR, Varney G, Butler JC. Decline in respiratory syncytial virus hospitalizations in a region with high hospitalization rates and prolonged season. Pediatr Infect Dis J 2006; 25: 1116-22.

[21] Singleton RJ, Bruden D, Bulkow LR. Respiratory syncytial virus season and hospitalizations in the Alaskan Yukon-Kuskokwim Delta. Pediatr Infect Dis J 2007; 26: 46-50.

[22] Wilfret DA, Baker BT, Palavecino E, Moran C, Benjamin DK Jr. Epidemiology of respiratory syncytial virus in various regions within North Carolina during multiple seasons. N C Med J 2008; 69: 447-52.

[23] Weber MW, Dackour R, Usen S, et al. The clinical spectrum of respiratory syncytial virus disease in The Gambia. Pediatr Infect Dis J 1998; 17: 224-30.

[24] Resch B, Pasnocht A, Gusenleitner W, Müller W. Rehospitalisations for respiratory disease and respiratory syncytial virus infection in preterm infants of 29-36 weeks gestational age. J Infect 2005; 50: 397-403.

[25] Hammer J, Numa A, Newth CJ. Acute respiratory distress syndrome caused by respiratory syncytial virus. Pediatr Pulmonol 1997; 23: 176-83.

[26] Kim KK, Frankel LR. The need for inotropic support in a subgroup of infants with severe life-threatening respiratory syncytial virus infection. J Invest Med 1997; 45: 469-73.

[27] Resch B, Gusenleitner W, Mueller WD. Risk of concurrent bacterial infection in preterm infants hospitalized due to respiratory syncytial virus infection. Acta Paediatr 2007; 96: 495-8.

[28] Kneyber MC, Brandenburg AH, de Groot R, et al. Risk factors respiratory syncytial virus associated apnoea. Eur J Pediatr 1998; 157: 331-5.

[29] Ralston S, Hill V. Incidence opf apnoea in infants hospitalized with respiratory syncytial virus bronchiolitis: a systematic review. J Pediatr 2009; 155: 728-33.

[30] Gleeson M, Clancy RL, Cox AJ, Gulliver SA, Hall ST, Cooper DM. Mucosal immune responses to infections in infants with acute life threatening events classified as 'near-miss' sudden infant death syndrome. FEMS Immunol Med Microbiol 2004; 42: 105-18.

[31] Ng Y, Cox C, Atkins J, Butler IJ. Encephalopathy associated with respiratory syncytial virus bronchiolitis. J Child Neurol 2001; 16: 105-8.

[32] Resch B, Gusenleitner W, Mandl C, Müller W. Epidemiology of respiratory syncytial virus infection in Southern Austria. Pediatr Infect Dis J 2000; 19: 587-8.
[33] Wert SE. Normal and abnormal structural development of the lung. In: Polin RA, Fox WW, Abmann SH, Eds. Fetal and Neonatal Physiology. Philadelphia: Saunders 2004; pp. 784-94

[34] Ballow M, Cates KL, Rowe JC, Goetz C, Desbonnet C. Development of the immune system in very low birth weight (less than $1500 \mathrm{~g}$ ) premature infants: concentrations of plasma immunoglobulins and patterns of infections. Pediatr Res 1986; 20: 899-904.

[35] Groothuis JR, Gutierrez KM, Lauer BA. Respiratory syncytial virus infection in children with bronchopulmonary dysplasia. Paediatrics 1988; 82: 199-203.

[36] Navas L, Wang E, de Carvalho V, Robinson J. Improved outcome of respiratory syncytial virus infection in a high-risk hospitalized population of Canadian children. Pediatric Investigators Collaborative Network on Infections in Canada. J Pediatr 1992; 121: 348-54.

[37] Wang EE, Law BJ, Stephens D. Pediatric Investigators Collaborative Network on Infections in Canada (PICNIC) prospective study of risk factors and outcomes in patients hospitalized with respiratory syncytial viral lower respiratory tract infection. J Pediatr 1995; 126: 212-19.

[38] Joffe S, Escobar GJ, Black SB, Armstrong MA, Lieu TA. Rehospitalization for respiratory syncytial virus among premature infants. Pediatrics 1999; 104: 894-9.

[39] Figueras-Aloy J, Carbonell-Estrany X, Quero-Jiménez J, et al. IRIS Study Group. FLIP-2 Study: risk factors linked to respiratory syncytial virus infection requiring hospitalization in premature infants born in Spain at a gestational age of 32 to 35 weeks. Pediatr Infect Dis J 2008; 27: 788-93.

[40] Flamant C, Hallalel F, Nolent P, Chevalier JY, Renolleau S. Severe respiratory syncytial virus bronchiolitis in children: from short mechanical ventilation to extracorporeal membrane oxygenation. Eur J Pediatr 2005; 164: 93-8.

[41] Horn SD, Smout RJ. Effect of prematurity on respiratory syncytial virus hospital resource use and outcomes. J Pediatr 2003; 143: S133-41

[42] Willson DF, Landrigan CP, Horn SD, Smout RJ. Complications in infants hospitalized for bronchiolitis or respiratory syncytial virus pneumonia. J Pediatr 2003; 143 (Suppl): S142-S9.

[43] Nachman SA, Navaie-Waliser M, Qureshi MZ. Rehospitalization with respiratory syncytial virus after neonatal intensive care unit discharge: A 3-year follow-up. Pediatrics 1997; 100: E8.

[44] The PREVENT Study Group. Reduction of respiratory syncytial virus hospitalization among premature infants with bronchopulmonary dysplasia using respiratory syncytial virus immune globulin prophylaxis. Pediatrics 1997; 99: 93-9.

[45] The IMpact-RSV Study Group: Palivizumab, a humanized respiratory syncytial virus monoclonal antibody, reduces hospitalisation from respiratory syncytial virus infection in high-risk infants. Pediatrics 1998; 102: 531-7.

[46] Thomas M, Bedford-Russell A, Sharland M. Hospitalisation for RSV infection in ex-preterm infants-implications for use of RSV immune globulin. Arch Dis Child 2000; 83: 122-7.

[47] Carbonell-Estrany X, Quero J. IRIS Study Group. Hospitalization rates for respiratory syncytial virus infection in premature infants born during two consecutive seasons. Pediatr Infect Dis J 2001; 20: 874-9.

[48] Pedraz C, Carbonell-Estrany X, Figueras-Aloy J, Quero J; IRIS Study Group. Effect of palivizumab prophylaxis in decreasing respiratory syncytial virus hospitalizations in premature infants. Pediatr Infect Dis J 2003; 22: 823-7.

[49] Pedersen O, Herskind AM, Kamper J, Nielsen JP, Kristensen K. Rehospitalization for respiratory syncytial virus infection in infants with extremely low gestational age or birthweight in Denmark. Acta Paediatr 2003; 92: 240-2.

[50] Singleton R, Dooley L, Bruden D, Raelson S, Butler JC. Impact of palivizumab prophylaxis on respiratory syncytial virus hospitalizations in high risk Alaska Native infants. Pediatr Infect Dis J. 2003; 22: 540-5.

[51] Law BJ, Langley JM, Allen U, et al. The Pediatric Investigators Collaborative Network on Infections in Canada study of predictors of hospitalization for respiratory syncytial virus infection for infants born at 33 through 35 completed weeks of gestation. Pediatr Infect Dis J 2004; 23: 806-14.

[52] Doering G, Gusenleitner W, Belohradsky BH, Burdach S, Resch B, Liese JG. The risk of respiratory syncytial virus-related hospitaliza- 
tions in preterm infants of 29 to 35 weeks' gestational age. Pediatr Infect Dis J 2006; 25: 1188-90.

[53] Greenough A, Cox S, Alexander J, et al. Health care utilisation of infants with chronic lung disease, related to hospitalisation for RSV infection. Arch Dis Child 2001; 85: 463-8.

[54] Thompson WW, Shay DK, Weintraub E, et al. Mortality associated with influenza and respiratory syncytial virus in the United States. JAMA. 2003; 289: 179-86

[55] Stensballe LG, Devasundaram JK, Simoes EA. Respiratory syncytial virus epidemics: the ups and downs of a seasonal virus. Pediatr Infect Dis J 2003; 22: S21-32.

[56] Thorburn K. Pre-existing disease is associated with a significantly higher risk of death in severe respiratory syncytial virus infection. Arch Dis Child 2009; 94: 99-103.

[57] Sampalis JS. Morbidity and mortality after RSV-associated hospitalizations among premature Canadian infants. J Pediatr 2003; 143 (Suppl): S150-6.

[58] Kapikian AZ, Mitchell RH, Chanock RM, et al. An epidemiologic study of altered clinical reactivity to respiratory syncytial (RS) virus infection in children previously vaccinated with an inactivated RS virus vaccine. Am J Epidemiol 1969; 89: 405-21

[59] Kim HW, Canchola JG, Brandt CD, et al. Respiratory syncytial virus disease in infants despite prior administration of antigenic inactivated vaccine. Am J Epidemiol 1969; 89: 422-35

[60] Groothuis JR, Simoes EAF, Levin MJ, et al: Prophylactic administration of respiratory syncytial virus immune globulin to high-risk infants and young children. N Engl J Med 1993; 329: 1524-30.

[61] American Academy of Pediatrics. Respiratory syncytial virus immune globulin intravenous: indications for use. Pediatrics 1997; 99 : 645-50

[62] Johnson S, Oliver C, Prince GA, et al. Development of a humanized monoclonal antibody (MEDI-493) with potent in vitro and in vivo activity against respiratory syncytial virus. J Infect Dis 1997; 176: $1215-24$.

[63] Cohen AH, Resch B. Experience with palivizumab prophylaxis for preventing RSV disease. J Respir Dis 2000; 2: S24-S9

[64] Frogel M, Nerwen C, Boron M, et al. Improved outcomes with home-based administration of palivizumab: results from the 20002004 Palivizumab Outcomes Registry. Pediatr Infect Dis J 2008; 27: $870-3$
[65] Lacaze-Masmonteil T, Rozé JC, Fauroux B; French Pediatricians' Group of Synagis Patients' Name-Based Programs. Incidence of respiratory syncytial virus-related hospitalizations in high-risk children: follow-up of a national cohort of infants treated with Palivizumab as RSV prophylaxis. Pediatr Pulmonol 2002; 34: 181-8.

[66] Golombek SG, Berning F, Lagamma EF. Compliance with prophylaxis for respiratory syncytial virus infection in a home setting. Pediatr Infect Dis J 2004; 23: 318-22.

[67] Manzoni P, Sala U, Gomirato G, Coscia A, Fabris C. Optimal Timing and Dosing Intervals of Palivizumab in Premature Neonates: Still Some Work to Do. Pediatrics 2005; 115; 1439-40.

[68] Wu SY, Bonaparte J, Pyati S. Palivizumab use in very premature infants in the neonatal intensive care unit. Pediatrics 2004; 114 Available at: www.pediatrics.org/cgi/content/full/114/5/e554.

[69] Parnes C, Guillermin J, Habersang R, et al. Palivizumab prophylaxis of respiratory syncytial virus disease in 2000-2001: results from The Palivizumab Outcomes Registry. Pediatr Pulmonol 2003; 35: 484-9.

[70] Committee on Infectious Diseases. From the American Academy of Pediatrics: Policy statements--Modified recommendations for use of palivizumab for prevention of respiratory syncytial virus infections. Pediatrics 2009; 124: 1694-701.

[71] Simões EA, Carbonell-Estrany X, Fullarton JR, et al. A predictive model for respiratory syncytial virus (RSV) hospitalisation of premature infants born at 33-35 weeks of gestational age, based on data from the Spanish FLIP Study. Respir Res 2008; 9: 78.

[72] Sampalis JS, Langley J, Carbonell-Estrany X, et al. Development and validation of a risk scoring tool to predict respiratory syncytial virus hospitalization in premature infants born at 33 through 35 completed weeks of gestation. Med Decis Making 2008; 28: 47180 .

[73] Paes B, Steele S, Janes M, Pinelli J. Risk-Scoring Tool for respiratory syncytial virus prophylaxis in premature infants born at 33-35 completed weeks' gestational age in Canada. Curr Med Res Opin 2009; 25: 1585-91.

[74] Stensballe LG, Fullarton JR, Carbonell-Estrany X, Simões EA. Population based external validation of a european predictive model for respiratory syncytial virus hospitalization of premature infants born 33 to 35 weeks of gestational age. Pediatr Infect Dis J 2009. [Epub ahead of print].

Received: June 28, 2011

Revised: October 12, 2011

Accepted: October 27, 2011

(C) Resch et al.; Licensee Bentham Open.

This is an open access article licensed under the terms of the Creative Commons Attribution Non-Commercial License (http://creativecommons.org/licenses/ by-nc/3.0/) which permits unrestricted, non-commercial use, distribution and reproduction in any medium, provided the work is properly cited. 